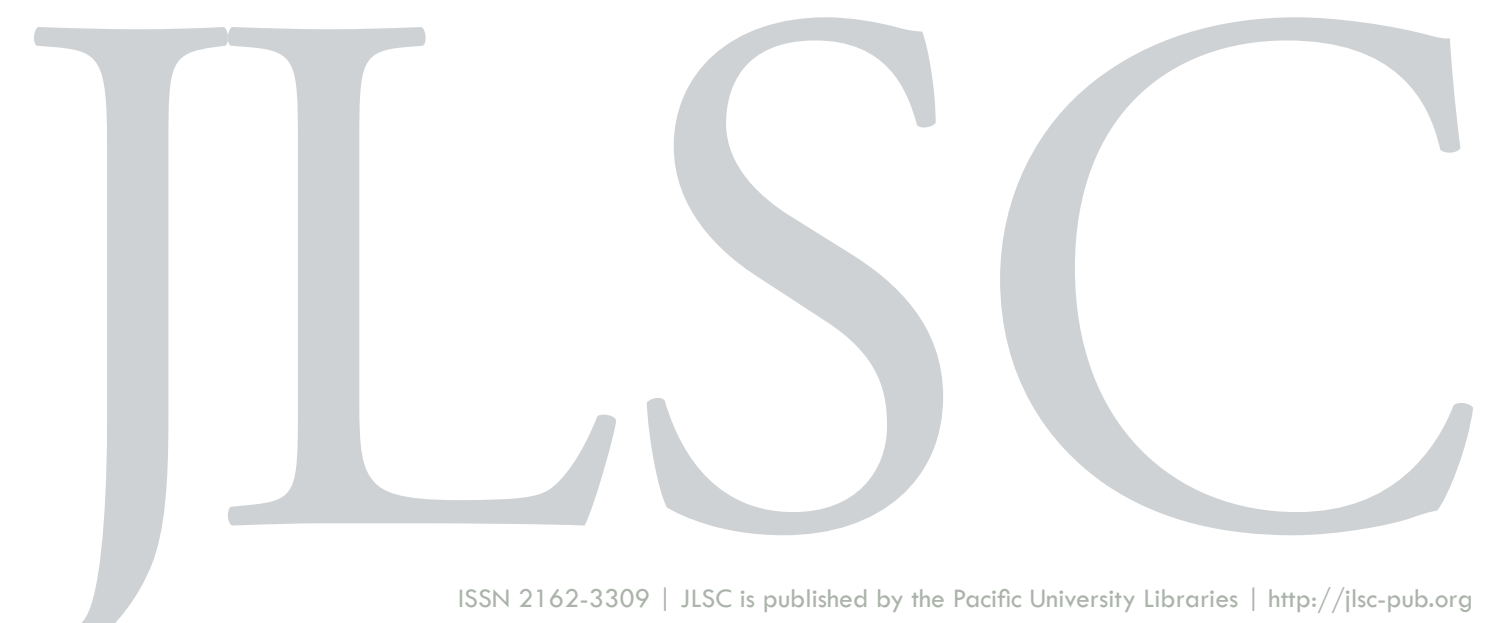

Volume 8, General Issue (2020)

\title{
Using Open Pedagogy to Engage LIS Students: A Case Study
}

\section{Christopher Hollister}

Hollister, C. (2020). Using Open Pedagogy to Engage LIS Students: A Case Study. Journal of Librarianship and Scholarly Communication, 8(General Issue), eP2357. https://doi.org/10.7710/2162-3309.2357

This article underwent fully-anonymous peer review in accordance with JLSC's peer review policy. 


\title{
RESEARCH
}

\section{Using Open Pedagogy to Engage LIS Students: A Case Study}

\author{
Christopher Hollister \\ Interim Head of Scholarly Communication, University at Buffalo, Buffalo NY
}

INTRODUCTION This case study describes the experimental use of open pedagogy to teach graduate-level library and information science (LIS) students in a newly developed course on international and comparative librarianship. Open pedagogy is the theory and practice of engaging students as creators of course content rather than requiring them to be consumers of it. In this case, students created an open textbook; each student authored a chapter about libraries and the field of librarianship in an assigned non-North American country. The textbook was developed under a Creative Commons license as an open educational resource (OER), allowing free use, remixing, and repurposing in future sections of the course or in similar courses offered in LIS programs at other institutions. METHOD The author used student perception data collected from a voluntary survey instrument and from a compulsory reflection paper assignment to assess the efficacy of implementing an open pedagogy framework in the course. RESULTS Collected data suggests the experiment produced results perceived by the majority of students as efficacious in the given context. DISCUSSION Students were enthusiastic in their embrace of creating renewable versus disposable coursework, and they expressed great satisfaction with the course outcomes of contributing to the professional literature, building the discipline's nascent OER record, and having a publication to feature in their curricular and professional dossiers. CONCLUSIONS Massive shifts in teaching and learning demand radical transitions. Open pedagogy is a response to that demand that requires additional research and experimentation.

Received: 01/06/2020 Accepted: 05/08/2020

Correspondence: Christopher Hollister, 324 Lockwood Memorial Library, North Campus, Buffalo, NY 14260, cvh2@buffalo.edu

(C) 2020 Hollister. This open access article is distributed under a Creative Commons Attribution 4.0 License (https:// creativecommons.org/licenses/by/4.0/) 


\section{IMPLICATIONS FOR PRACTICE}

1. Library educators are encouraged to provide leadership in the area of open education by responding to shifts in teaching and learning environments that demand innovation and an emphasis on the role of students and instructors as co-creators of knowledge.

2. Open pedagogy represents an opportunity for LIS educators to embrace the need for informal, collaborative, and networked learning that can take place anywhere and at any time.

3. Emerging discourse suggests the potential for learning benefits made possible through the implementation of an open pedagogy framework in a variety of postsecondary course settings.

\section{INTRODUCTION}

In 2019, the author created a new course on international and comparative librarianship for master's-level library and information (LIS) students. Initial stages of course development were stymied by what the author deemed to be the substandard quality of supporting professional literature. This assessment of the literature was in part validated by Lor's (2014) critical analysis, which concluded "...the body of work comprising comparative LIS lacks connectedness and has so far failed to contribute as much to the theoretical basis of library and information science as it should have" (p. 26). The author would argue that much of the supporting literature was also outdated, Western-centric, and generally lacking in vitality that is deserving of the subject matter. To address these concerns, the author adopted an open pedagogy framework for the course that involved students creating their own textbook. Each student was responsible for authoring a chapter of the text that featured libraries and librarianship in an assigned non-North American country. Furthermore, the text was developed under a Creative Commons license as an open educational resource (OER), allowing free use, remixing, and repurposing in future sections of the course or in similar courses offered in LIS programs elsewhere.

\section{Hypothesis}

Proponents of open pedagogy advance it as a form of experiential learning in which students demonstrate greater understanding of and engagement with course content through the act of creating it. Given the aforementioned inadequacies of the extant literature on international and comparative librarianship, the promise of such an outcome moved the author to explore open pedagogy as an alternative course design framework. The particular context of teaching Master's-level LIS students provided additional reasoning. The author estimated that the development of an open textbook as a central focus would bring the coursework into greater alignment with students' interests in a variety of ways, as discussed below.

A review of relevant course syllabi from other American Library Association (ALA)-accredited programs revealed a near universal emphasis on students producing traditional term papers, or what 
Wiley (2013) and other leaders in the open education community describe as "disposable assignments." Wiley, Webb, Weston \& Tonks (2017) clarified the definition of disposable assignments as those that "both faculty and students understand will ultimately be thrown away" (p. 62). Such coursework has no life or utility beyond one graded assignment in one class. By comparison, the author of this case study speculated that students would embrace the notion of creating renewable coursework, or that which provides a desired learning benefit and continues as an OER for the ongoing benefit of future LIS students and instructors.

The author conjectured that the creation of an open textbook would be viewed by LIS students as an uncommon opportunity to participate in the professional discourse by filling a gap in the literature and by contributing to the discipline's nascent OER record. Authoring open textbook chapters would also help students to fulfill their LIS program curricular portfolio requirements, and it would serve as a featured addition to their professional dossiers. Furthermore, the author ventured that creating an OER would mesh well with LIS students' professional values, given the library field's abiding ethics concerning equitable access to information (ALA, 2019).

Finally, the author imagined that LIS students would support the proposition of using open pedagogy as a classroom experiment. Specifically, they would support an experiment conducted in the setting of a public research university, and undertaken for the general purposes of improving teaching and learning and advancing the open education movement. There is no published research on the use of open pedagogy in specific LIS courses, nor are there any broader studies about experimenting with open pedagogy in ALA-accredited programs. Accordingly, this case study is exploratory in nature. The conjecture described here constitutes a multidimensional hypothesis about the efficacy of using open pedagogy in an international and comparative librarianship course for master's-level LIS students.

\section{LITERATURE REVIEW}

The literature on open pedagogy is limited overall, but it has expanded and evolved in recent years. Scholarly use of the term "open pedagogy" can be traced back to Elliot's (1973) contention that an open classroom is one in which instructors and students are co-creators of classroom discussion. Similar discourse continued on a narrow thread until 2009, when the educational potential of emerging web technologies inspired Hodgkinson-Williams and Gray (2009) to forecast that the practice of open pedagogy was set to play a transformational role in the collaboration between students and instructors. A variety of frameworks for teaching and learning innovation emerged during this same period, supporting Hodgkinson-Williams and Gray's projection. Nichols and Cator (2009) advanced the notion of challenge-based learning, which encourages students to work collaboratively and to leverage the technology they use in their daily lives to produce content for the purpose of addressing real-world problems. Blaschke and Hase (2015) proffered the complementary idea of self-determined learning, an informal and student-centered strategy in which pupils identify their own learning goals, implement problem-solving plans, and reflect upon their learning experiences. More foundationally, Herrington and Herrington (2006) proposed the conception of 
authentic learning, which encourages students to explore, discuss, and meaningfully construct sharable works that are relevant to learners in their own lives. Rule (2006) clarified the parameters of authentic learning by identifying its essential components: exercises involving real-world scenarios, use of inquiry and critical thinking skills, student engagement and participation in a community of learners, and student-empowered and directed project work. As argued by Ossiannilsson (2018), these advancements in teaching and learning are cornerstones of open pedagogy and they are realized within that framework.

Recent discourse emphasizes the importance of OER and the associated permissions granted by their open licensing as a required component of open pedagogical practice. As noted by Wiley (2013), "This is the ultimate test of whether or not a particular approach or technique can rightly be called 'open pedagogy"' (para. 17). There is broad consensus on this point (Cronin, 2017; DeRosa \& Robison, 2017; Hegarty, 2015; Ossiannilsson, 2018). Accordingly, open pedagogy is generally understood as a set of teaching and learning practices that is only possible in the context of free access and the permissions that are characteristic of OER (Wiley \& Hilton, 2018). This is the operational definition of open pedagogy as it is explored in the present case study.

Cronin (2017) examined open pedagogy in the broader context of open educational practices (OEP), for which Ehlers (2011) gave the following, widely accepted definition: "OEP are defined as practices which support the (re)use and production of OER through institutional policies, promote innovative pedagogical models, and respect and empower learners as co-producers on their lifelong learning path" (p. 4). DeRosa and Jhangiani (2017) simplified the notion of OEP as a set of practices that accompany either the use of OER or the adoption of open pedagogy, and to that effect they provided the pivotal example of student-created textbooks. Several case studies on this particular practice are featured in Mays's edited volume, A Guide to Making Open Textbooks with Students (2017), which describes student-created textbooks in a variety of courses: art history, biology, economics, Latin American literature, philosophy, and others. The literature yields additional examples of student-created textbooks in business (Randall, Johnson, West, \& Wiley, 2013), public health (Hill, 2019), and technical writing (Johnson \& Hooper, 2018). As argued by Cronin (2017), however, "...there has been little empirical research on individual educators' use of OEP for teaching in higher education" (p. 15). To this point, Wiley and Hilton (2018) called for future research that contributes to the understanding of the efficacy of open pedagogical practice, or what they termed "OER-enabled pedagogy." Specifically, Wiley and Hilton asked whether students who are required to create OER find such assignments valuable, interesting, motivating, or rewarding, if making those assignments publicly available generates greater mastery of the subject matter, and if there are any drawbacks to the practice (p. 143-144). Notwithstanding the exploratory nature of the present case study and its speculative hypotheses, the author also addresses these important questions as part of this investigation.

Finally, Hegarty (2015) harnessed the existing research to establish a rationale for the term "open pedagogy," and further to introduce a model for open pedagogy that consisted of specific, but interrelated and necessary elements. Now commonly known as the "eight attributes of open pedagogy," those elements are as follows: participatory technologies, openness and trust, innovational and cre- 
ativity, sharing ideas and resources, connected community, learner generated, reflective practice, and peer review. Together, these attributes established a structure for instructors to understand and implement open pedagogical practice in their own circumstances. Accordingly, they were adopted to inform the development of the experiment described in this paper.

\section{METHODS}

This study took place during the summer term of 2019 in the context of a course on international and comparative librarianship for master's-level LIS students in the University at Buffalo's Department of Information Science. The course was six weeks in length and it was delivered asynchronously online by way of the university's licensed courseware platform. The study involved an open pedagogy experiment in which students were required to create their own course textbook as an OER. The goals of the investigation were as follows:

- Assess the efficacy of implementing an open pedagogy framework in the context described;

- Identify the elements of open pedagogy that served as motivating, valuable, or problematic factors for students; and

- Contribute to the greater understanding of open pedagogical practice in the postsecondary environment.

The author collected data in two forms to achieve the stated goals. To generate quantitative data on students' perceptions of their participation in the experiment, the author administered an anonymized, online survey at the end of the semester, which consisted of ten closed-ended questions (see Appendix 1). Participation in the survey was voluntary, and results were collected by way of the university's courseware platform. Students were also required to submit papers in which they were asked to reflect deeply and more holistically on the motivating, valuable, or problematic aspects of their open pedagogy experience (see Appendix 2). Those papers were submitted anonymously, and they were likewise collected through the courseware platform. The reflection assignment was compulsory because that form of student contemplation and observation is a critical component of the open pedagogy framework (Hegarty, 2015).

This study was approved by the University at Buffalo's Institutional Review Board. The associated research data is publicly viewable on the Open Science Framework repository (Hollister, 2020).

\section{LIMITATIONS}

Logic holds that the views of students who participated in this study were affected by levels of engagement with the author and with course subject materials. Despite anonymous data collection and voluntary participation in the survey, the fact that data was collected through a courseware platform suggests the likelihood of selection bias. It is also noteworthy that this is a highly contextu- 
alized investigation involving 26 graduate-level LIS students in an asynchronously delivered online course. The results are therefore not generalizable.

\section{OPEN PEDAGOGY EXPERIMENT}

The LIS students in this study were required to apply theoretical and research-based elements of the international and comparative librarianship course as part of their open pedagogy exercise. The author-also the course instructor-adopted numerous strategies to align the structure of this undertaking with Hegarty's (2015) "eight attributes of open pedagogy." To begin, the textbook was developed as a single artifact on the Google Docs platform, which, combined with a class-wide discussion board and smaller working group wikis, established the necessary element of a connected community. Complementary, interactive assignments helped to foster a desirable culture of openness and innovation. The author used consistent, positive messaging to help build students' creative confidence and to encourage their sense of self-determination with the project. Together, the active, community platforms and an open, trusting culture of the class permitted a critical aspect of the experiment to take place: peer review. The final version of this class project, titled International Libraries: An Open Textbook, was published as an open monograph on the University at Buffalo's institutional repository under the Creative Commons license CC: BY-NC-SA, and it continues as an OER for the benefit of future sections of the course or for similar course offerings elsewhere.

The development of International Libraries: An Open Textbook was a semester-long experiment involving the following sequence of related assignments: country selection, annotated bibliography, chapter outline, first draft, peer review, final draft, and reflection paper. Given the parameters of a six-week summer term, this was an ambitious undertaking. Textbook creation was preceded by lectures, readings, and activities introducing students to the applied concepts of open pedagogy, OER, renewable versus disposable coursework, Creative Commons copyright licensing, and experimental course design. As part of their first week's coursework, students elected to develop the text under the Creative Commons license CC: BY-NC-SA. The author will confess to a measure of evangelism as it pertains to these concepts and the overall experiment; however, students in this setting were easily persuaded, enthusiastic, and willing participants.

The original and unedited version of International Libraries: An Open Textbook remains on Google Drive. After the course concluded, the author prepared final editions in Microsoft Word and PDF formats; these were modified from the original to align with criteria for posting to the University at Buffalo's institutional repository. Some of the original chapters were excluded from the public edition to accommodate students who did not wish to have their work openly available, to account for students who did not sign a required institutional agreement allowing for digital conversion, access, storage, and preservation, and to respect reasonable standards of academic quality. Numerous images and figures were removed: some for copyright compliance and others for more practical matters of design, length, and accessibility requirements. Only minor edits were made to the actual text to address misspellings, glaring grammatical errors, and stylistic inconsistencies. To maintain the integrity of students' coursework, no further adjustments were made. 
There is one additional note concerning the availability of International Libraries: An Open Textbook The author is presently exploring options to publish a Candela or Pressbooks version of this work on the State University of New York's OER Ready-to-Adopt Courses repository.

\section{RESULTS}

Twenty-six students completed the international and comparative librarianship course described in this study. Seventy-seven percent $(N=20)$ of the students participated in the voluntary survey, and all of them submitted the compulsory reflection paper assignment. The results from these two data sources are complementary in nature; together, they address the author's speculative hypotheses and Wiley and Hilton's (2018) more general questions about students' perspectives on the use of open pedagogy in the classroom. The results are therefore presented a corresponding manner. Survey results are reported numerically, and student reflections are illuminated through description and the use of relevant excerpts. The fortuitous number of students also permitted the use of an anonymous attribution convention with letters of the alphabet: e.g., "Student A" through "Student Z."

As seen in Table 1, 100\% (N=20) of the survey participants reported that the experiment described in this paper was their first experience with open pedagogy. To this point, Student P recounted, "Going into this class, I did not know what the term 'open pedagogy' meant and had no experience with the concept." Several students admitted to an initial sense of unease, as with Student M who confessed, "At first, I was confused and apprehensive when I read the syllabus, as it did not seem as though there was much structure in the course." Further indications of early semester discomfort were evident. Sixty percent $(n=12)$ of the survey respondents indicated that the public nature of their coursework caused a measure of anxiety, although many reported in their reflection papers that their dispositions evolved as the semester unfolded, as exemplified by Student W: "It [the open pedagogy assignment] proved to be a stimulating challenge rather than a stress inducing burden." More critically, three students shared their reservations about writing open textbook chapters on the libraries and the field of librarianship in other countries. To this point, Student O admitted, "As an American, I've also wondered whether I had the right to attempt an explanation of a story that rightly belongs to [citizens of another country].”

\begin{tabular}{lcc} 
Survey questions & Yes & No \\
\hline $\begin{array}{l}\text { Was the International Libraries: An Open Textbook chapter assignment your first } \\
\text { experience with open pedagogy? }\end{array}$ & 20 & 0 \\
\hline Do you recognize educational value of using open pedagogy in this course? & 20 & 0 \\
\hline $\begin{array}{l}\text { Did the open availability of International Libraries: An Open Textbook chapter cause } \\
\text { any discomfort or anxiety for you personally? }\end{array}$ & 12 & 8 \\
\hline Do you recommend the use of open pedagogy in future sections of this course? & 20 & 0 \\
\hline
\end{tabular}

Table 1. Student perceptions of the open pedagogy experiment Note. $(N=20)$ 
Notwithstanding some initial expressions of discomfort, $100 \%(N=20)$ of the survey respondents indicated that they recognized the educational value of using open pedagogy in the course, and $100 \%$ of them recommended the use of open pedagogy in future sections. To these points, Student G emphasized, "The benefits of creating coursework provides the foundation for a deep understanding of the material at hand," and Student B proclaimed, "It is my sincere hope that future sections of this class will not only add to this resource [the open textbook] but improve and update its chapters." Furthermore, $100 \%(N=20)$ of the respondents answered affirmatively to the question, "Do you like the idea of moving beyond the traditional model of the final paper, the term paper, or the so called 'disposable assignment'?" This particular aspect of the experiment generated voluminous student commentary. Student R remarked, "Overall, the open pedagogy assignment was a good experience. I truly appreciated having more than a 'dead', one-and-done paper to show for this class." Indeed, the term "disposable assignment," as presented to students in this class, appeared to resonate deeply. Several reflection papers included term, including that of Student G, who observed, “The final or 'disposable assignment' has been a topic of discussion for quite some time. Students often ask, 'What purpose does this have?' or 'When am I ever going to use it again?' If teachers can't provide an honest answer for those questions, then it's time to re-evaluate the quality of our teaching methods." One hundred percent $(N=20)$ of the survey respondents indicated that they benefitted from receiving peer feedback on their open textbook chapters, and all but one $(n=19)$ specified that they gained from evaluating their classmates' chapters. The topic of peer review also spawned considerable discussion in students' reflection papers. Student N's lengthy contribution fairly represented the perceptions of others:

“The peer feedback was important to me because I got to focus on my classmates' work, see how they interpreted the assignment, learn about other countries, and connect with my classmates. I found the feedback I received to be very helpful because it provided me with both encouragement and friendly constructive criticism. The constant feedback every week from students of the professor helped me to know I was on the right track, too.”

There were problematic aspects of peer review as well. Students J and L were uncertain of the extent to which they were required to acknowledge or respond to peer evaluations, Students $S$ and $U$ expressed a desire for more guidance on how to provide critical feedback to their peers, and Student $\mathrm{G}$ recommended an earlier date for peer evaluations to be completed.

One hundred percent $(N=20)$ of the survey respondents answered affirmatively to the question, "Does publishing a textbook chapter as a product of this course appeal to you?" To this point, Student L underscored, "It is satisfying to know I can put the chapter on my curriculum vitae, unlike other work I have done in this program," and Student $\mathrm{N}$ beamed, "I cannot believe that I contributed to this textbook. It is such an awesome feeling knowing that I was able to help fill a gap in the literature in my field while still in school. I am proud of this chapter and I am excited to show my school what I accomplished by taking this course." 
The copyright aspect of this open pedagogy experiment required some unpacking. One hundred percent $(N=20)$ of the survey respondents answered 'Yes' to the question, "Does making your textbook chapter available under a Creative Commons license as an open educational resource appeal to you?" Interestingly, however, the word "copyright" appeared nowhere in any of the students' reflection papers. Instead, students' perceptions of Creative Commons and OER in general were represented in sentiments like those offered by Student E: "Being a part of creating open content for future sections of the course and for the greater learning community is rewarding. It is a nice feeling to know that your hard work will be shared with the world and that other people can benefit from it."

Ninety percent $(n=18)$ of the survey respondents agreed that Google Docs should continue as the collaborative platform for developing OER in the course moving forward. As noted by Student M: "The choice to work on Google Docs was a relief. It is a common workspace that most people are already familiar with. Typically, online classes will require an obscure download of a program that will never be used again, that the student must arbitrarily master for one assignment in one class." However, many students conveyed frustrations with the platform in their reflection papers: for instance, slow response times, constant reloading and display shifting, and difficulty editing and maintaining a consistent format. Clearly, these issues correlated with times of high usage. To address, this, Student R suggested the potential utility of chunking out different sections of the open textbook and creating smaller peer review working groups.

One final theme demands reporting. There were no survey questions regarding the length of the course. Significantly, however, $65 \%(n=17)$ of the student reflections included relative commentary. The nature of that input has implications with respect to the efficacy of adopting an open pedagogy framework in the course. Some student reflections, like that of Student M, described this dynamic as a favorable one: "It helped that the course was an intense six weeks. If it were longer, the open pedagogy would not be effective; a longer course may actually dampen the content and make it seem too dull." However, the majority of students who commented on the length of the course held an opposing view. Student P's blunt input on the matter captured the more subtly communicated reflections of others who were similarly minded: "The six-week aspect was the most frustrating. I constantly felt like I did not have enough time. Not only to research and write, but also to step away and clear my head before revising."

\section{DISCUSSION}

The results of this exploratory investigation appear to give credence to the author's multidimensional hypothesis on use of open pedagogy in an international and comparative librarianship course for master's-level LIS students. To begin, the evidence is compelling that students in this study ascribed a positive learning experience to the implementation of an open pedagogy framework, and they held for its continued use in future sections of the course. Students were enthusiastic in their embrace of creating renewable versus disposable coursework. They also expressed satisfaction with contributing to the professional literature, building the discipline's nascent OER record, and having a publication to feature in their curricular and professional dossiers. 
It is also clear that the open pedagogy experiment yielded varying, but very real levels of student anxiety. To a degree, that discomfort can be attributed to the ambitious nature of requiring students to complete their textbook chapters in a short timeframe; students provided effusive feedback on this point. Some students also specified feelings of anxiety over the public nature of their coursework. Notwithstanding the reflections that showed most of these students came to accept and even embrace this aspect of open pedagogy, some did not, and to that effect, two students opted out of the open textbook that was published on the author's institutional repository. Three students articulated a sense of unease with the notion of American students writing textbook chapters about libraries and the field of librarianship in non-North American countries. That sensitivity is reinforced by Bordonaro's (2017) assessment of the literature, which concluded, "...the ideas surrounding what international librarianship means seem to come mainly from librarians practicing in developed nations, principally in North America" (p. 5).

The stated goals of this research were to assess the efficacy of implementing an open pedagogy framework in an international and comparative librarianship course, to identify elements that served as motivating, valuable, or problematic factors for students, and to generate greater understanding of open pedagogical practice. The collected data suggests the experiment produced results perceived by the majority of students as efficacious in the given context. In their reflection papers, students qualified their overall open pedagogy experience as "cool," “engaging," "engrossing," "exciting," "helpful," “motivating," "positive," "productive," “real," "relevant," "rewarding," "stimulating," "timely," "unique," "useful," and "worthwhile." Students imputed particular value to the aspects of content creation, renewable assignments, and publishing as a product of the course. Albeit, the public nature of the coursework caused a general sense of anxiety, the most problematic aspect of the open pedagogy experiment appears to have been the ambitious timeline. Moving forward, a traditional 14-week semester may be more suitable in terms of providing the necessary adjustment period for this framework.

The remaining question is whether this study provided a greater understanding of open pedagogical practice in the postsecondary environment. On this general point, Wiley and Hilton (2018) specifically asked the open education research community to investigate whether students who are required to create OER find such assignments valuable, interesting, motivating, or rewarding, if making those assignments publicly available generates greater mastery of the subject matter, and if there are any drawbacks to the practice (p. 143-144). With the exception of subject matter mastery, those questions are addressed in the context of the present study. As argued by Friedlander and Serban (2004), the assessment of student learning, or subject mastery, is a longstanding and significant challenge. It is therefore critical for the advancement of discourse in this area to avoid exaggerated claims and to focus on the reasonable interpretations of relevant data. Accordingly, the author would argue that students' reflections provided the most applicable information concerning their learning within the framework described in this paper. The evidence is compelling that students derived particular educational benefits made possible by the open pedagogy experiment, or more precisely, that they perceived there to be learning benefits from the experience. To this point, Student G offered the following remarks, which resemble and overlap with the majority of students' reflections: 
"The concept of open pedagogy is extremely relevant to a deep understanding of subject matter. In order to obtain a firm grasp on the material, the process of 'hunting and gathering' the material, critically analyzing the data, and then arranging it into a coherent, cohesive chapter was far more meaningful than say reading a prewritten chapter in a textbook and taking notes. The benefits of creating coursework provides the foundation for a deep understanding of the material at hand."

\section{CONCLUSIONS}

Koseoglu and Bozkurt's (2018) expansive review of the literature showed a surprisingly limited body of research on open educational practices, prompting them to emphasize the need to build collective knowledge across the disciplines. To this point, the present investigation contributes new information to the unexplored area of open pedagogical practice in LIS education. The study describes an experiment in which graduate-level LIS students created their own textbook in an international and comparative librarianship course. Each student was required to write a chapter about libraries and the field of librarianship in a non-North American country, and the completed textbook was developed as an OER for the benefit of future sections of the course. Student perceptions of their participation in this enterprise were collected and analyzed. The collected data suggests the experiment produced results perceived by students as efficacious in the given context. Students were particularly enthusiastic in their embrace of creating renewable versus disposable coursework, and they expressed great satisfaction with a variety of other course outcomes.

The open pedagogy assignment also generated a noteworthy measure of student anxiety. To a degree, that discomfort can be attributed to the ambitious nature of requiring students to complete their textbook chapters in a condensed summer term. Many students also identified feelings of unease as it pertained to the public nature of their coursework. Despite the data that showed most of these students came to accept and even embrace this aspect of an open pedagogy framework, a small number did not, and as a result, two students opted not to include their chapters in the open textbook. This dynamic seems to align with Jhangiani's (2017) assertion that "adopting open pedagogy is simultaneously liberating and terrifying" to students. Though, as Jhangiani continued, "It [open pedagogy] creates a foundation for our students to begin to invest more deeply, think more critically, work more collaboratively, and communication more accessibly-exactly the skills needed" (para. 19).

Apparent pathways for future research present themselves in the context of this study. It will be useful to investigate whether International Libraries: An Open Textbook is adopted, adapted, or emulated in future sections of the course at the author's university or elsewhere. If so, it will be valuable to know the nature of that use, any resulting products, and students' perceptions. The focus of this research was based on student perspectives. Moving forward, it may be beneficial to solicit and examine input form LIS instructors who experiment with open pedagogy in their own courses. Given the nascent status of the library field's OER record, it might also be worthwhile to track the web 
traffic and citation metrics associated with the open textbook in this study, and to compare those dimensions with other OER textbooks in LIS or in other disciplines. In addition, the ongoing need to assess the quality of OER products is implied.

This study is situated in a time of massive shifts in teaching and learning that demand radical transitions. There is growing support for models that support informal, collaborative, and networked learning that can take place anywhere at any time. Open pedagogy, as it is defined and explored in this paper, is a response to that momentum; it represents changes in learning environments where "knowledge is co-created and facilitated through mutual interaction and reflection" by students and instructors (Ehlers, 2011, p. 4). Considerable research and experimentation is needed to interrogate this outlook, and in particular, to assess the efficacy of open pedagogical practice in the various teaching and learning circumstances of today's postsecondary environment.

\section{ACKNOWLEDGEMENTS}

The author wishes to express his sincere gratitude the international and comparative librarianship students who provided a leap of faith with their participation in the open pedagogy experiment described in this paper. Albeit, this was a new and sometimes uncomfortable learning exercise for this progressive group of students, they embraced the ideals of open education, renewable coursework, and educational experimentation and innovation. The resulting publication, International Libraries: An Open Textbook, is an accomplishment for which they should be proud. The author also wishes to thank Jessica Kruger for her generous counsel on open pedagogical practice, and Karlen Chase for her guidance in preparing and publishing the open textbook.

\section{REFERENCES}

American Library Association. (2019). Access to library resources and services. Retrieved from http://www. ala.org/advocacy/intfreedom/access

Blaschke, L., \& Hase, S. (2015). A holistic framework for creating $21^{\text {st }}$ century self-determined learners. In B. Gros \& M. Kinshuk (Eds.), The future of ubiquitous learning: Learning designs for emerging pedagogies (pp. 25-40). Berlin: Springer. https://doi.org/10.1007/978-3-662-47724-3 2

Bordonaro, K. (2017). International librarianship home and abroad. Cambridge, MA: Chandos Publishing. https://doi.org/10.1016/B978-0-08-101896-5.00003-X

Cronin, C. (2017). Openness and praxis: Exploring the use of open educational practices in higher education. International Review of Research in Open and Distributed Learning, 18(5), 15-34. https://doi.org/10.19173/irrodl.v18i5.3096

DeRosa, R., \& Jhangiani, R. (2017). Open pedagogy. In Mays, E. (Ed.), A guide to making open textbooks with students (pp. 7-20). Montreal: Rebus Community. 
DeRosa, R., \& Robison, S. (2017). From OER to open pedagogy: Harnessing the power of open. In R.S. Jhangiani \& R. Biswas-Diener (Eds.), Open: The philosophy and practices that are revolutionizing education and science (pp. 115-124). London: Ubiquity Press. https://doi.org/10.5334/bbc.i

Ehlers, U.-D. (2011). Extending the territory: From open educational resources to open educational practices. Journal of Open, Flexible and Distance Learning, 15(2), 1-10. Retrieved from http://www.jofdl.nz/ index.php/JOFDL/article/view/64

Elliot, J. (1973). Is instruction outmoded? Cambridge Journal of Education, 3(3), 169-181. https://doi.org/10.1080/0305764730030305

Friedlander, J., \& Serban, A. M. (2004). Meeting the challenges of assessing student learning outcomes. New Directions for Community Colleges, 126, 101-109. https://doi.org/10.1002/cc.158

Hegarty, B. (2015). Attributes of open pedagogy: A model for using open educational resources. Educational Technology, 55(4), 3-13.

Herrington, A., \& Herrington, J. (2006). Authentic learning environments in higher education. Hershey, PA: Information Science Publishing. https://doi.org/10.4018/978-1-59140-594-8

Hill. D. (2019). SUNY honors SPHHP’s Kruger for teaching innovations. UBNow. Retrieved from http:// www.buffalo.edu/ubnow/stories/2019/07/kruger-fact2-award.html

Hodgkinson-Williams, C., \& Gray, E. (2009). Degrees of openness: The emergence of open educational resources at the University of Cape Town. International Journal of Education and Development Using Information and Communication Technology, 5(5), 101-116.

Hollister, C. (2020). Research data for "Using open pedagogy to engage LIS students: A Case Study". Open Science Framework. doi: 10.17605/OSF.IO/VSNB4.

Jhangiani, R. (2017). Ditching the "disposable assignment" in favor of open pedagogy. [Web blog]. https://doi.org/10.31219/osf.io/g $4 \mathrm{kfx}$

Johnson, F., \& Hooper, M. (2018). iFixit with the library: Partnering for open pedagogy in technical writing. OLA Quarterly, 24(3), 13-17. https://doi.org/10.7710/1093-7374.1950

Koseoglu, S., \& Bozkurt, A. (2018). An exploratory literature review on open educational practices. Distance Education, 39(4), 441-461. https://doi.org/10.1080/01587919.2018.1520042

Lor, P. J. (2014). Revitalizing comparative library and information science: Theory and metatheory. Journal of Documentation, 70(1), 25-51. https://doi.org/10.1108/JD-10-2012-0129

Mays, E. (Ed.). (2017). A guide to making open textbooks with students. Montreal: Rebus Community.

Nichols, M., \& Cator, K. (2009). Challenge based learning. [White paper]. Cupertino, CA: Apple. Retrieved from http://cbl.digitalpromise.org/wp-content/uploads/sites/7/2016/12/CBL Paper 2008.pdf 
Ossiannilsson, E. (2018). Ecologies of openness: Reformations through open pedagogy. Asian Journal of Distance Education, 13(2), 103-119.

Randall, D.L., Johnson, J.C., West, R.E., \& Wiley, D. (2013). Teaching, doing and sharing project management: The development of an instructional design project management textbook. Educational Technology, 53(6), 24-28.

Rule, A. (2006). The components of authentic learning. Journal of Authentic Learning, 3(1), 1-10.

Wiley, D. (2013). What is open pedagogy? [Web blog]. Retrieved from https://opencontent.org/blog/ archives/2975

Wiley, D., \& Hilton, J. (2018). Defining OER-enabled pedagogy. International Review of Research in Open and Distributed Learning, 19(4), 133-147. https://doi.org/10.19173/irrodl.v19i4.3601

Wiley, D., Webb, A., Weston, S., \& Tonks, S. (2017). A preliminary exploration of the relationships between student-created OER, sustainability, and students' success. International Review of Research in Open and Distributed Learning, 18(4), 60-69. https://doi.org/10.19173/irrodl.v18i4.3022 


\section{APPENDIX A \\ Survey Questions (Yes or No answers)}

- Was the International Libraries: An Open Textbook chapter assignment your first experience with open pedagogy?

- Do you recognize educational value of using open pedagogy in this course?

- Did the open availability of your International Libraries: An Open Textbook chapter cause any discomfort or anxiety for you personally?

- Do you recommend the use of open pedagogy in future sections of this course?

- Do you like the idea of moving beyond the tradition model of the final paper, the term paper, or the so-called "disposable assignment"?

- Do you feel that you gained from receiving peer feedback on your International Libraries: An Open Textbook chapter?

- Do you feel that you gained from providing peer feedback to student peers on their International Libraries: An Open Textbook chapters?

- Does publishing a textbook chapter as a product of this course appeal to you?

- Does having your International Libraries: An Open Textbook chapter available under a Creative Commons license as an open educational resource appeal to you?

- Do you recommend using Google Docs as a platform for future open textbook assignments? 


\section{APPENDIX B \\ Reflection Paper Assignment}

\section{General Instructions}

Write a brief reflection paper on the International Libraries: An Open Textbook experience. Examples of specific reflections might include any or all the following:

- Experience with learning course material through open pedagogy

- Benefits or consequences of creating open educational resources and using them as course learning materials

- Benefits or consequences of creating open content for future sections of the course at the University at Buffalo or elsewhere, or for the greater learning community

- Rethinking the final paper, the term paper, or the "disposable assignment"

- Ease or challenge of using open pedagogy in an online course environment

- Ease or challenge of creating course content in a condensed, six-week summer term

- Ease or challenge of retrieving the necessary supporting materials through the University at Buffalo Libraries delivery services

- Ease or challenge of using the Google Docs platform

- Learning course content from student peers; gaining and providing peer feedback

- Publishing student course work in the open education environment

- Finishing the course with a published book chapter to add to a résumé or a curriculum vitae

\section{Specific Instructions}

- Use Microsoft Word.

- Write a 200-300 word reflection.

- Be honest and forthright.

- Avoid the surface-level "I learned a lot" kind of reflection.

- Save the reflection paper with the following name convention: LastName. Reflection (e.g., Hollister.Reflection.docx).

- Use the submission tool for this assignment on the [institution name] course site. 
The grading rubric of the International Libraries: An Open Textbook reflections will include the following elements:

- Professionalism of writing style (grammar, usage, logic, tone, narrative style)

- Substantive reflection 